Cómo citar / How to cite: Poveda Navarro, A.M. 2020. Signum/sigillum eucarístico de la ecclesia visigoda Santa María de Elo (El Monastil, Elda). Antigüedad y Cristianismo 37, 29-44. https:/doi.org/10.6018/ayc.458751

\title{
SIGNUM/SIGILLUM EUCARÍSTICO DE LA ECCLESIA VISIGODA Santa María de Elo (El Monastil, Elda)
}

\section{EUCHARISTIC SIGNUM/SIGILLUM OF THE VISIGOTIC ECCLESIA SANTA María of Elo (El Monastil, Elda)}

\author{
Antonio Manuel Poveda Navarro \\ Museo Arqueológico de Elda, \\ Elda, España \\ ant.man.poveda@gmail.com \\ orcid.org/0000-0002-5519-0468
}

Recibido: 22-7-2020

Aceptado: 7-11-2020

\section{RESUMEN}

En este breve trabajo se presentan un sigillum/signum cerámico utilizado para producir obleas con el fin de usarlas en el ritual cristiano litúrgico visigodo y el significado eclesiástico de la leyenda que se conserva parcialmente, que parece evidente hace mención a la Santa Virgen María, de modo que sería la primera ocasión en que su advocación aparece, ya en el s. VII d. C. en la parte oriental del Reino Visigodo toledano. Explico su decoración, morfología y significado ideológico paleocristiano, también el significado y valor de su aparición en un contexto de culto cristiano con existencia de un edificio sacro para el mismo.

Palabras clave: Complejo eclesiástico monástico y episcopal, Visigodos, Eucaristía, Sello de obleas, Iconografía paleocristiana, Elo.

\begin{abstract}
This short work presents a ceramic sigillum / signum used to produce wafers, in order to use them in the Visigothic Christian liturgical ritual and the ecclesiastical meaning of the legend that is partially preserved, what seems evident makes mention of the Santa Virgen María, so that it would be the first time that her invocation appears, already in the VII century d. C., in the Eastern part of the Visigothic Kingdom of Toledo. I explain its decoration, morphology and early Christian ideological meaning, also the meaning and value of its appearance in a context of Christian worship, with the existence of a sacred building for it.
\end{abstract}

Keywords: Ecclesiastical monastic and episcopal complex, Visigoths, Eucharist, Wafer seal, early Christian iconography, Elo. 


\section{SUMARIO}

1. Información y contexto del hallazgo. 2. Características y significado del sello eucarístico.

3. Conclusiones.

\section{INFORMACIÓN Y CONTEXTO DEL HALLAZGO}

Recientemente se ha podido identificar el que parece ser único sello cerámico paleocristiano de la Hispania Gothorum dedicado a marcar hostias para la liturgia.

Se trata de un disco cerámico que se conserva parcialmente, pues ha perdido prácticamente un tercio de su dimensión original. La pieza fue hallada durante la campaña de excavaciones arqueológicas desarrollada durante el año 2011-2012, en concreto a comienzos de este último año, en el yacimiento arqueológico de El Monastil (Elda) (Poveda 1988; 1996, 415-426; 2009, 579-581; 2010, 65-86; Poveda y Márquez 2006, 63-73; Reynolds 1993), en su parte más elevada o acrópolis, en el ambiente 49 , a escasos $30 \mathrm{~m}$ del sureste del edificio identificado como iglesia (Poveda 2000, 574-575; 2000a, 93-96; 2003, 113-125; 2006, 110-115; Poveda, Márquez y Peidró 2013, 1153-1162) de la segunda mitad del s. VI d. C., cuando el lugar estaba ocupado por bizantinos vinculados al importante grupo localizado en la vecina antigua colonia romana de Ilici (la Alcudia, Elche), a tan sólo $34 \mathrm{~km}$. de distancia del lugar del hallazgo del sello que presento (Fig. 1), en la que fuera una antigua ciuitas peregrina, citada en los itinerarios latinos romanos y altoimperiales (Itinerario de Antonino, la Geografía de Guido, el Anónimo de Rávena y la Tabula Peutingeriana) como Elo (ad Ello, ed Elle, Eloe, Dello) (Cortés 1836, 437; Roldán 1975; Sillières 1990, 363), que se ha de interpretar como un centro urbano hispano-romano modesto, cuya denominación latina correcta sería la de Elum, que en la fase histórica de bizantinos y visigodos se transformaría en un castrum, que erigió un monasterion bizantino por probable decisión del poder imperial protobizantino, asentado en Ilici bajo el gobierno de Justiniano I. Posteriormente, expulsados los imperiales de Bizancio, será el reino godo de Toledo quien aproveche el lugar y su modesta infraestructura eclesiástica para crear un efímero episcopado, pues poco después Ilici también fue liberada de los bizantinos, circunstancia que le permitió recuperar su territorio diocesano y asumir por fusión la sede elotana, dando lugar a que un único obispo firmase con el título de ambas sillas episcopales, situación que se prolongará hasta la llegada de los musulmanes. Precisamente un grupo de ellos se estableció en El Monastil, Elo, reutilizando espacios y elementos arquitectónicos, incluso para su uso como modesta mezquita rural y creando un modesto centro religioso islámico del tipo conocido como al-munastir (Poveda 2007, 181-201).

Desde el año 1983 hasta hoy hemos podido desarrollar una investigación que comenzó identificando objetos paleocristianos del Museo Arqueológico de Elda, que procedían de las actividades de recuperación de materiales arqueológicos que aficionados a la arqueología del Centro Excursionista Eldense habían realizado entre los años 1959 y 1980, en el yacimiento arqueológico de El Monastil, ya entonces propuesto sede de un efímero obispado godo (Llobregat 1973, 46-51; 1977, 94-96; 1980, 397-413; 1983, 236-237), e incluso sin conocer la existencia de ese yacimiento, defender que se situaría en Elda (García Moreno 1981, 327). De este breve episcopado visigodo se conocen obispos que firmaban en los concilios toledanos del s. VII d. C. como representantes de la ecclesia elotana (de la población tardorromana de Elo).

Las excavaciones arqueológicas autorizadas desde el año 1984 por la Conselleria de Cultura valenciana nos permitieron, con la colaboración del arqueólogo P. Reynolds, exhumar la parte 


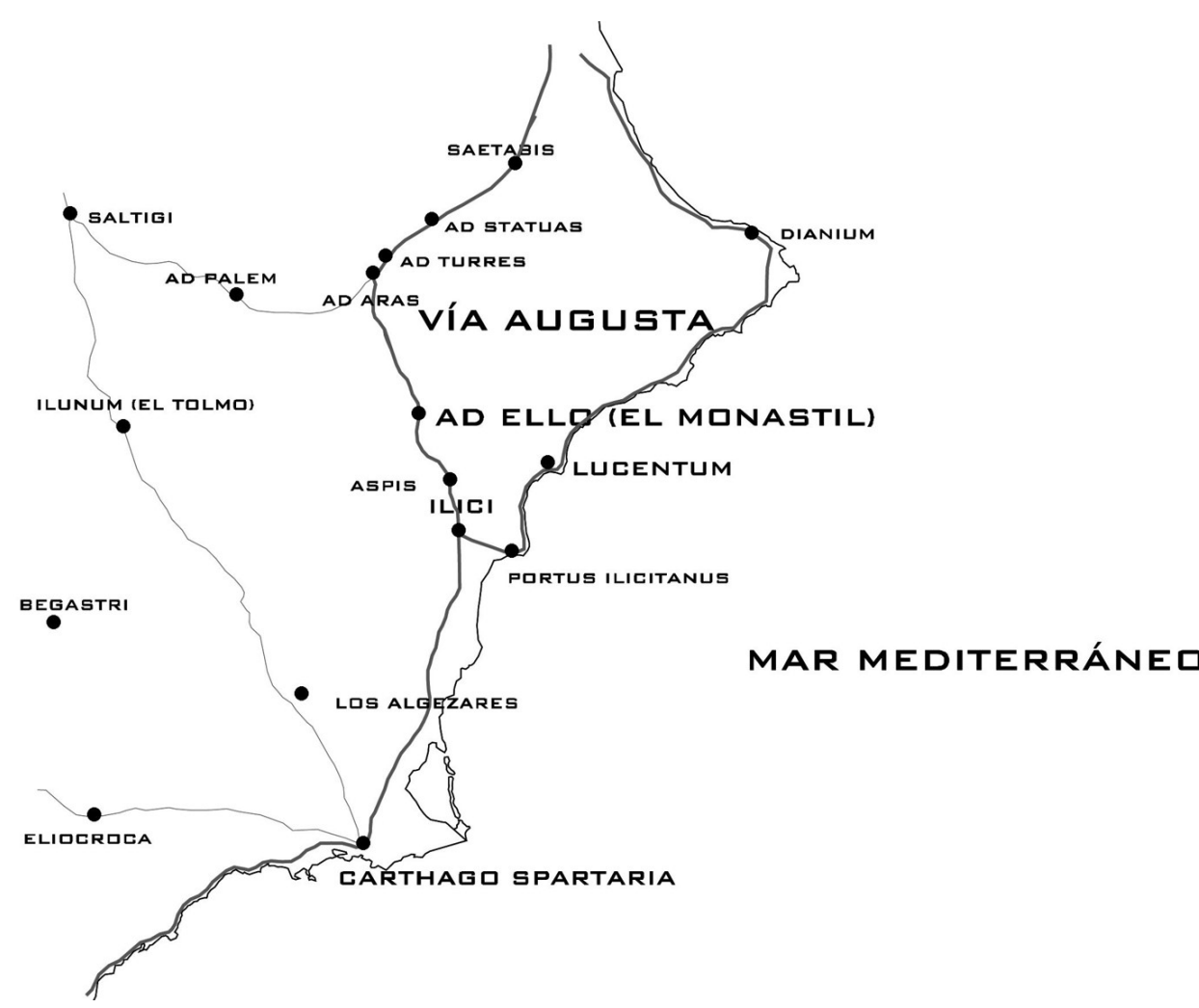

Figura 1. Mapa con la situación de El Monastil (Elo) en la geografía poblacional y viaria romana del sureste de Hispania.

conservada de la planta de una iglesia con ábside de herradura o ultrasemicircular, a la que en los años 90 del pasado siglo asociamos elementos arquitectónicos reutilizados en fase islámica por las estancias próximas, clara prueba de la importante actividad de spolia caso de los fragmentos de un altar de mármol egeo del tipo sigmático polilobular o ferro di cavallo, típico de finales del s. VI d. C. y el s. VII d. C. en iglesias y monasterios de zonas bizantinas (Chalkia 1991); también la basa de una columna octogonal de tipología bizantina, que apareció reutilizada en el centro de una estancia postvisigoda; además, durante esa década y la siguiente se fue identificando el posible mobiliario del usado en ese lugar de culto al que se asocia los mencionados elementos arquitectónicos citados (Poveda 1991, 611-626; 2000, 574-579; 2000a, 93-96; 2003, 113-125; 2006, 95-115; 2009, 280-281; Poveda 2019, 305-312; Márquez y Poveda
2000, 177-184): una pyxide de marfil oriental, posiblemente alejandrina, con relieves de la escena de Hércules y la cierva capturada de Cerinia, ejemplo del sincretismo del héroe clásico con Cristo que se generalizó en fase protobizantina y fue extendido por las conquistas mediterráneas de Justiniano, perdurando con frecuencia durante la Edad Media (Poveda 2016, 617-630). La indudable adscripción bizantina de este contexto arqueológico hizo pensar que podíamos identificar y vincular con el mismo a tres exagia bizantinos que presentaban signos escritos en griego para indicar su valor ponderal.

Reconocido el conjunto como perteneciente al último tercio del s. VI d. C., se produjo otro hallazgo arqueológico fundamental $\mathrm{y}$ complementario, a $250 \mathrm{~m}$. al oeste de la salida del castrum bizantino, se exhumó parte de una necrópolis del último tercio de ese siglo y principios del VII d. C., en dos de sus tumbas 
se recuperaron tres anillos de cobre con signos griegos, una cruz griega en dos de ellos y la letra sigma en el otro.

Estos contextos cronológicos y de culto cristiano, nos permitió defender que algunos antiguos hallazgos de cerámicas claras norteafricanas, como un cáliz (actualmente desaparecido) y una fuente o pátena con seis cruces impresas en su fondo interno, han de pertenecer al mobiliario eucarístico de la iglesia que allí se ha identificado, fechada en el s. VI d. C.

Pues bien, en ese mismo contexto hay que citar que recientemente ha sido hallado un sello cerámico (Fig. 2) para obleas eucarísticas (stampo eucaristico), que contiene relieves con un pavo real y parte de un grafito con texto que inicialmente parecía de lengua griega, pero que finalmente se ha podido interpretar como letras latinas de una abreviatura latina cristiana. La presencia segura de estas obleas en la iglesia, da lugar a que pueda defenderse que una pequeña hoja de hierro existente entre los fondos antiguos, pertenece al típico cuchillito (lancia), habitual en ámbitos bizantinos, sobre todo monásticos, empleado para cortar y manipular las hostias / ostias; también se ha podido reinterpretar otro objeto de los fondos antiguos, una cucharilla o cochlear de un material que imita a la plata, el peltre (aleación de cobre, estaño, amonio y plomo), de las usadas para manipular las obleas sagradas, recoger algunas gotas de agua o incluso de vino. Entre esos mismos fondos hemos identificado también una campanilla de bronce de las que se hacen sonar en ciertos momentos de la liturgia y la eucaristía, y también un anillo-llave de bronce, muy probablemente relacionado con la cerradura del pequeño cofre donde se conservaban las obleas consagradas que habían sobrado tras la eucaristía, que son siempre dejadas en una pyxide o cajita cilíndrica (pyxide a torre, pyxide hostaria) como la antes citada, que se deposita en un espacio siempre cercano al altar.

Se trata de un conjunto de instrumentos litúrgicos y bizantinos sin parangón en la Península Ibérica y en el Mediterráneo occidental, que demuestra el gran valor político, religioso, económico y cultural que Elo, (El Monastil), desempeñó en esta región del sureste hispano durante la segunda mitad del s. VI d. C. y el primer cuarto del s. VII d. C.

\section{Características y Significado DeL SELLO EUCARÍSTICO}

En ese contexto histórico y arqueológico hay que insertar, entender y explicar la aparición de este unicum de entre los hallazgos de signa pistoris, es decir, entre los sellos de cerámica que eran empleados para estampar una marca sobre panecillos y pasteles desde época púnica y todo el periodo romano, que en su fase paleocristiana adoptó la costumbre de los eulogia, marcar panecillos que así eran bendecidos (Deonna 1919) para los peregrinos. Es bien conocido el hallazgo en la ciudad romana de Ostia Antica de más de cuatrocientos sellos de panadero en diferentes locales (Pasqui 1906) que funcionaban de pistrinae, como también sabemos del hallazgo de los numerosos panes carbonizados que muestran la marca del panadero que trabajaba en uno de esos locales en Pompeya y Herculano (Overbeck 1886).

Estos cuños o tampones se realizaban en metal pero sobre todo en cerámica, con ellos se estampaba una marca de fábrica o comercial, aunque también un buen grupo se empleó para el culto imperial y la conmemoración del dies natalis del emperador, al igual que se usó abundantemente con una iconografía que mostraba figuras de divinidades o de animales y símbolos que representaban a esas deidades, de modo que es un instrumento habitual e importante en los rituales religiosos, pues servirán para crear impresiones con valor religioso, un valor sagrado, pudiendo ser en ocasiones reconocido un significado votivo en los objetos que han recibido las imágenes o símbolos que han sido impresos (Drexel 1916, 17-22; Alföldi 1938; Lillo 1981, 188189). Esta actividad de sellar objetos blandos, 


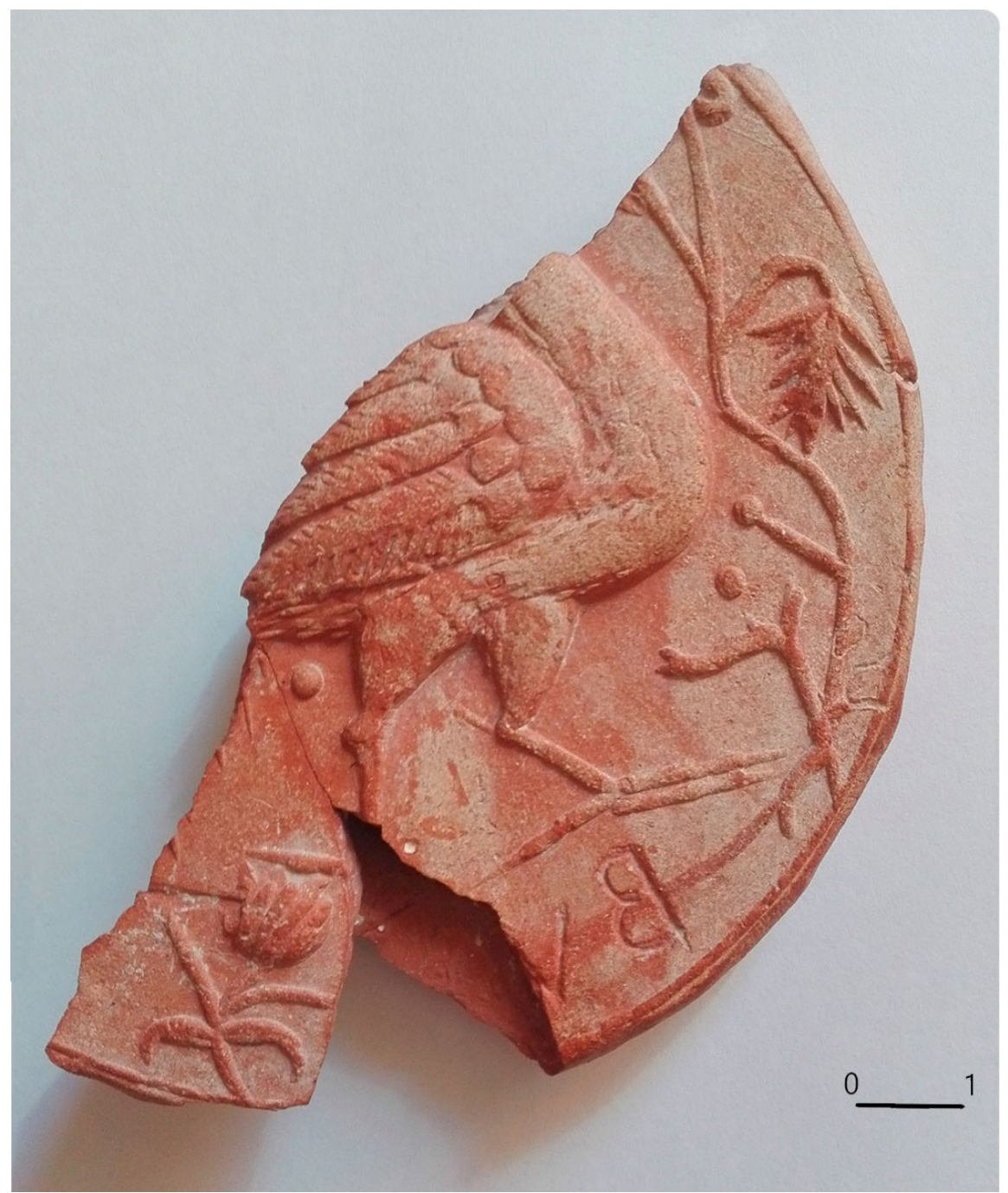

Figura 2. Fotografía del sello para obleas eucarísticas, de El Monastil (Elo) (fotografía del autor).

especialmente panes o panecillos, será asumida y desarrollada más amplia y numerosamente desde el s. IV d. C. y la fase tardo-romana en la que se produce la llegada e implantación de la religión cristiana, debido a la aparición litúrgica de las obleas a consagrar en cada iglesia o monasterio.

En el s. IV, en ámbito oriental, se fue implantando la idea de que las obleas tenían que ser pequeños panes redondos y totalmente planos, sobre los que se hizo habitual emplear sellos que imprimiesen símbolos cristianos para que adoptase el aspecto sagrado de pan eucarístico, caso de nuestro sello circular de terracota. Estos cuños son instrumentos mayoritariamente creados y usados por los cristianos del Mediterráneo occidental en sus iglesias, al menos a partir de los siglos IV y V d. C., como ilustran bien el sello en piedra de Brindisi (Jurlaro 1961, 77-82) y otro de bronce de Spira, de poco después se conoce otro hallado en Arles (Francia), del V o VI siglo, y el de Djebana (Túnez), del s. VI (Galavaris 1970, 53-62), otro sello pero de bronce y de ese 
mismo siglo se halló en Conimbriga (Portugal) (Pessoa 2017, 189), más tardío es el sello de El Monastil, del s. VII. A partir de los siglos VII y VIII, los sellos dejan impresa en las obleas una decoración siempre en composiciones cuatripartitas, a partir de una cruz central, siempre en ambiente bizantino o del rito greco-oriental, en cambio será así a partir del s. IX en el rito latino, y a partir del s. XII se caracterizarán por su pequeño formato y fijar definitivamente que han de ser circulares (Jurlaro 1961; Di Berardo 2000). Estos datos permiten establecer para el sello de El Monastil una cronología ligeramente anterior, de hacia los primeros años del s. VII, pues no coincide su tamaño y morfología con las de esas épocas. Además, existe un argumento que creemos evidentemente incontestable, las excavaciones que hemos realizado en este yacimiento, han permitido demostrar que no hay ningún edificio de culto cristiano cuya datación sea anterior a la segunda mitad del s. VI d. C. (Poveda 2000; 2003; 2019; Poveda, Márquez y Peidro 2013), cuando al parecer son los bizantinos los que ocupan el castrum y crean un monasterio de rito grecooriental, posteriormente fue ocupado por los visigodos en su avance desde Toledo, creando la denominada sede episcopal elotana (Poveda 1991; 1996a; 2000a; 2003; Peidró 2008; 2008a), sería entonces cuando pudo producirse y usarse el sello cerámico que ahora se presenta.

El tipo de pasta o arcilla del sello es de color rojo-marrón, que se obscurece hacia su centro o núcleo, visualmente presenta un aspecto que podría hacer pensar que llegó procedente de un taller de cerámica del litoral del norte de África, pero el interesante grafito que muestra, con claros indicios de haberse realizado antes de la cocción cerámica, permite defender su producción local ad hoc para la iglesia del lugar. Presenta unas diminutas inclusiones como desgrasante, cuyo aspecto es de laminitas de mica plateada, que personalmente conocemos, incrustadas en la pasta o arcilla de cerámicas comunes romanas documentadas en el sureste hispano.
Se trata de un sello sin paralelos entre el conjunto de los sellos recuperados en Hispania y publicados a fecha de hoy (Gijón y Bustamante 2010). El objeto cerámico identificado que presentamos es de los sellos de diámetro más grande, conserva $11,5 \mathrm{~cm}$, si bien presenta indicios de poder llegar hasta cerca de $12 \mathrm{~cm}$, de modo que tiene unas dimensiones considerables pero sin alcanzar a los conocidos de mayor diámetro, que son los que alcanzan $17 \mathrm{~cm}$. El grosor es más normal y común en su parte plana y más delgada, $1,2 \mathrm{~cm}$, sobre el mismo borde. La pieza se va engrosando hacia el centro debido a la aparición de la decoración en altorelieve, además de que hacia la parte central posterior, la no decorada, se observa, a pesar de la fragmentariedad, que hay una clara tendencia al engrosamiento, pues debió de disponer de un mango o apéndice de aprensión en esa parte del disco que se ha perdido, en la parte conservada más central tiene $1,8 \mathrm{~cm}$. La zona posterior o reverso del disco cerámico no muestra decoración, presenta un gran número de digitaciones, evidentes huellas de su proceso de fabricación manual; en el mismo canto o borde se aprecia, en su parte más externa, una fina línea que lo recorre con fluctuaciones en su profundidad. El objeto se encuentra actualmente expuesto en una vitrina del Museo Arqueológico de Elda, en la sección bizantino-visigoda y paleocristiana.

En el centro del disco se representa un pavo real orientado hacia la derecha, al que le falta la cabeza y la mayor parte de su larga cola de plumas. Se acompaña de tallos o ramaje que rodea todo el borde del disco donde brotan un par de hojas de palma, de las que se contemplan en las palmeras jóvenes; también se observa la presencia de algunos frutos representados aislados y dispersos, a modo de piezas circulares desprendidas de un tallo o brotando del mismo, seguramente se trate de la representación de dátiles, pues están junto a tallos con hoja de palma, pero su aspecto es más de ser uva. Una fina línea en leve relieve recorre circularmente toda la parte superior 


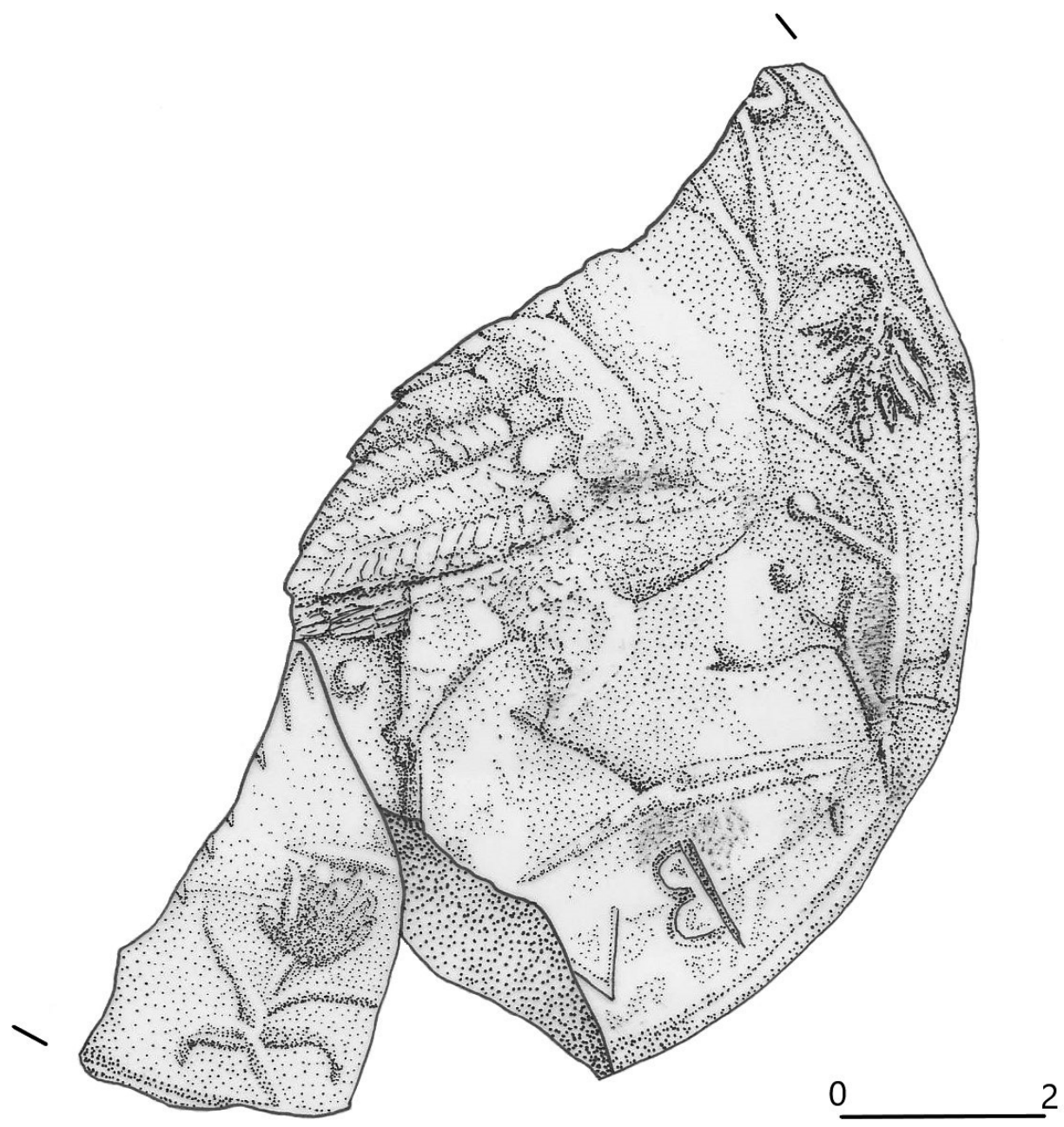

Figura 3. Dibujo de la parte anterior del sello de El Monastil (Elo) (dibujo de Gabriel Lara Vives).

del borde, circunscribiendo toda la decoración (Figs. 3 y 4 ).

En el arte bizantino paleocristiano el pavo real comparte con el ave fénix muchos de sus significados, pues ambas aves son símbolo de la resurrección, de la renovación, de la incorruptibilidad de la carne y de la inmortalidad del alma, por tanto de la eternidad (San Agustín, De Civitate Dei, XXI, $, 4,1)$, era también símbolo de orgullo y poder, de modo que se podía ver como al mismo Jesucristo. El origen está en un mito griego en el que un ave sagrada, parecida a un águila y un pavo, moría cada quinientos años para resurgir poco después de sus cenizas. Los autores latinos que trataron este mito lo difunden como ejemplo de la eternidad entendida como palingénesis, es decir, retorno cíclico continuo. De modo que es en esta idea donde los padres de la iglesia se basan para hablar del misterio de la resurrección de la carne. Literariamente quien mejor y más se extiende en esta cuestión es el Pseudo-Lactancio, en su De ave phoenice (Ferrua 1954-1955, 237-277; Van de Broek 


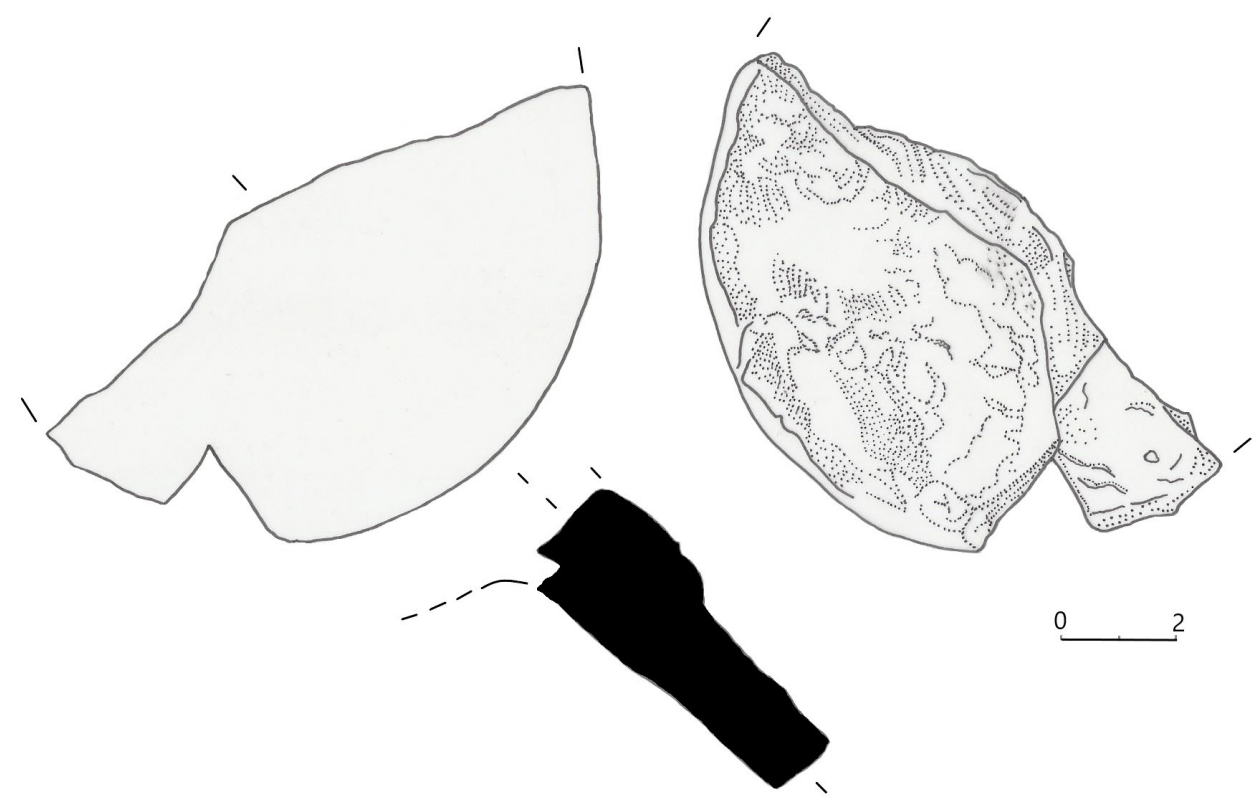

Figura 4. Dibujo de la parte posterior y sección del sello de El Monastil (Elo) (dibujo de Gabriel Lara Vives).

1972; Bisconti 1979, 21-40; 1991, 869-870; Diego 2010, 171-185). La presencia de la palma refuerza los mismos conceptos, pues comparte igual simbolismo y el significado en la cultura griega, a la que pertenecen los bizantinos. El pavo real, como el ave fénix, con la presencia de la palma y de algunas uvas, representa la alegoría de la resurrección, del paraíso y la eternidad (Chelli 2004, 73 y 95).

En lo que podríamos denominar el exergo o zona a los pies de la figura principal, es decir del pavo real, se observa el inicio de un grafito que muestra texto inverso, escrito de derecha a izquierda, la leyenda se conserva solamente en sus dos primeras letras. En un principio se pensó que esas letras eran de escritura griega, en concreto una beta y una ypsilón, sin embargo está demostrado que fue una errónea interpretación inicial nuestra, así se concluyó en el debate surgido después de impartir una conferencia en el workshop Pondera Online IV (diciembre 2019), realizado en la Universidad Católica de Lovaina la Nueva, en Bélgica, el profesor Matteo Campagnolo (Universidad de Ginebra), recordó a todos (y hay que agradecerlo) que no podía leerse By[zantium] porque todavía en la segunda mitad del siglo VI y principios del VII, no se habían comenzado a utilizar términos como Byzancio o bizantino, que las letras que se veían eran de lengua latina, en concreto una $b$ y una $v$, en formato de letra capital latina, afirmando que la lectura es clara, que se corresponden a una abreviatura de varias palabras: $B V[\ldots]$, que continuaría con al menos una tercera letra, que no podría ser más que una $M$, no hay más espacio, así pues se estima que es legítimo defender que la leyenda completa del grafito fuera $B V[M]$, correspondiéndose con la abreviación de una fórmula típicamente cristiana y bien conocida en la iglesia visigoda, pues era habitual encontrar referencias a la Virgen María con la expresión latina Beata Virgo María, por lo tanto sobre el disco cerámico para sellar ostias / hostias tendríamos que desarrollar las abreviaturas como B(eata) V(irgen (Maria), quizá con la voluntad de subrayar que es un sello para realizar las particiones del pan eucarístico del ritual de la liturgia de la iglesia goda del complejo episcopal de Elo, 
situada en la zona más elevada y encerrada en un hermético recinto. Por lo tanto, se está indicando la pertenencia de ese sello litúrgico a una iglesia que estaría bajo la advocación de la Bienaventurada o Santa Virgen María, como tantas y tantas iglesias visigodas que reciben esa denominación y advocación desde el s. VI y todo el s. VII, como se constata en inscripciones bien conocidas de Toledo o Mérida (Olmo 2007, 168-169; Balmaseda 2007, 200-201; Fernández 2007, 337-352; Sastre 2010, 30-44; Ihnat 2019).

Respecto a las dos únicas letras conservadas, faltando una tercera, que por el espacio desprendido de la cerámica es más que legítimo pensar que se trataría de una $M$, daría lo mismo que incluso no hubiera existido esta letra, se ha de tener en cuenta que entre toda la literatura cristiana, desde la más antigua hasta la más reciente, siempre que aparece una letra latina $B$ seguida de otra letra latina $V$, es la abreviatura Beata Virgo, como se explicará a continuación, siendo siempre su tercera letra latina acompañante y cierre de la abreviatura una $M$. Todos los diccionarios católicos sin excepción expresan que el término Beata Virgo Maria tiene por definición Bendita Virgen María, pero los mismos insisten en que a menudo se le cita igualmente como $B$ $V$, es decir, se menciona de modo reducido como Beata Virgo, o también $B M$, es decir, Beata Maria. El nombre propio Beata Virgo Maria, es un adjetivo de primera declinación con un sustantivo de tercera declinación y un sustantivo de primera declinación, que cuando declinó a genitivo se transformó en Beatae Virginis Mariae.

Estos deben ser los desarrollos probables de estas abreviaturas indicativas del gran culto mariano extendido por los godos, especialmente a partir del s. VI d. C., debe tenerse en cuenta que nuestro sello de El Monastil está datado, sin otra posibilidad, en la segunda mitad del s. VI o en el VII, es decir, en plena expansión del culto de la Virgen María por todos los territorios de la Hispania Gothorum, por lo tanto no es nada aventurado defender que las letras que constituyen la abreviatura latina, creada mediante un grafito en la superficie de este disco cerámico, se han de identificar con el desarrollo concreto de Beata Virgo [Maria]. En apoyo de esta idea vamos a aportar, a continuación, argumentos fehacientes bien conocidos en la Cristiandad.

En aquella época es buen ejemplo de todo este impulso mariano y citas a la Santa Virgen María, el propio Isidori Hispalensis (Allegoriae 139: PL 83, 117): "In misterio enim Ecclesiae, quae et ipsa iure mater vocatur et virgo, Beata Virgo Maria praecessit,..."

Por otro lado, desde antiguo la Iglesia se refiere a la "Beatissima Virgo Maria, ex qua Christus Dominus tomó aquella carne, que en este Sacramento, bajo las especies del pan y del vino, se contiene, se ofrece y se come, y todos los santos y las santas de Dios, especialmente los que sintieron más ardiente devoción por la divina Eucaristía ..." (CIC, can 801). Es evidente la gran presencia de la Virgen María en la Eucaristía, en la comunión entre los cristianos asistentes a la misma, por ello su aparición junto a Cristo en el sello de El Monastil está más que legitimada.

Este movimiento godo de difusión e implantación del culto a la Virgen María era además totalmente coincidente $y$ posiblemente incluso influenciado por los mismos romanos de Oriente, los bizantinos, que ya estaban en Septem (Ceuta) y en las islas Baleares, mostrando una devoción por la Virgen, la Theotokos de los romanos grecoorientales, muy patente y contundente, que en Constantinopla y el Mediterráneo oriental ya era un culto que estaba fuertemente asentado (Vallejo 1996). Se debe de tener en cuenta que en el Oriente Protobizantino, ese potente culto a la Virgen María se estaba extendiendo por todo el Mediterráneo, en Roma a principios del 600 , ya tenía un gran peso, unos años después, hacia la mitad del s. VII, el obispo Tajón de Zaragoza estuvo allí mismo y pudo traer influencias desde la propia Roma. Y todavía más importante pudo ser la estancia anterior, en pleno s. VI, del obispo Leandro de Sevilla, 
en la corte bizantina, donde la devoción por la virginidad de María estaba en auge, lo que pudo inspirar a Leandro a que a su vuelta escribiera su De institutione virginum. La doble virginidad de María es igualmente tema central de un tratado del obispo de Toledo, entre 657 y 667, Ildefonso, que fue el autor de De virginitate beatae Mariae, y desde luego es conocido el impulso que dio al culto de la Beata Virgo Maria en Toledo, siendo su basílica principal consagrada bajo su advocación. Por aquel tiempo, en el año 656, el rey Recesvinto, establecerá en el décimo concilio de Toledo la fiesta en Hispania a la Virgen María (Ihnat 2019). Por lo tanto, la abreviación de la fórmula epigráfica Beata Virgo [Maria], que aparece grabada sobre el sello perteneciente a la iglesia de Elo (El Monastil), sin problema forma parte de un contexto ideológico y religioso, y ello tanto si es un objeto de la fase bizantina como ya de la visigoda en el lugar, téngase en cuenta que aunque los imperiales orientales usaban principalmente la lengua griega, en el Mediterráneo occidental y en concreto en Hispania, realizaron bastantes documentos epigráficos en lengua latina (Vallejo 2012).

Todavía se puede contemplar otro signo escrito, a la derecha de las letras citadas aparece la letra $\mathrm{C}$, que aquí seguramente tiene un significado numérico, equivale en la cultura latina al numeral 100, cifra que debe tener su propio valor simbólico en el cristianismo primitivo, en la Biblia es un número que aparece en casi todos sus capítulos. También podría estar informando de alguna acción a realizar con el sello, algún significado que para nosotros es impreciso.

\section{Conclusiones}

El disco cerámico presenta una tipología, una morfología, característica de los sellos o tampones empleados para imprimir los símbolos e iconografía que se deseara sobre productos de panadería (pistrina) del periodo clásico romano. Pero si bien los elementos iconográficos son de origen pagano, precristiano, la composición que se ha conseguido plasmar y su pertenencia a la cultura paleocristiana, permiten distinguir este objeto del resto de signa pistoris.

En esa figuración ornamental destaca como principal signo la representación en el centro de la pieza de un pavo real, que ocupa casi toda la superficie decorativa. Esta ave posee una enorme carga ideológica y simbólica, comparte en origen la mayoría de los mismos significados que la mitológica figura del ave fénix, ambas surgen en fases antiguas dentro del paganismo, pero a partir del s. II d. C., serán absolutamente asumidas en la iconografía paleocristiana, principalmente en las pinturas de las catacumbas y en multitud de relieves, habitualmente sobre sarcófagos cristianos, en todo caso siempre en ámbitos funerarios, lo que en buena medida alerta y anuncia de su principal significado en el cristianismo, la resurrección y la eternidad.

La figura del pavo real es de profundas raíces clásicas, se le relaciona con Argos, a su muerte la diosa Hera, para inmortalizar a su gran servidor, trasladó sus ojos al ave que le estaba consagrada (Grimal 1966, 46, 170 y 239).

En la Antigüedad el pavo real era visto como un claro ejemplo de la inmortalidad. Plinio el Viejo, en su Naturalis Historia, vinculaba el renacer del pavo real a su anual renovación de sus plumas, de modo que era un excelente ejemplo de resurrección; por su parte San Agustín, en su De Civitate Dei, explicaba en un pasaje que su carne era incorruptible (Chelli 2004, 95). Estas ideas de recuperación, de renovación, por tanto de resurrección y eternidad, tuvieron un gran predicamento y aceptación en el arte paleocristiano tardoantiguo y altomedieval, sería muy largo realizar un listado con las veces que aparece el pavo real en las pinturas de las Catacumbas de Roma, así como en multitud de mosaicos cristianos.

Los primitivos cristianos convirtieron al pavo real en el símbolo de la vida eterna, asociándolo al alma del buen cristiano. Además, 
como se le suele representar individualmente o en pareja, bebiendo de una gran copa o kantharos, en cuyo interior se interpreta que alberga el vino y el pan para la comunión, es un icono importante y fácil de vincular con esta y su celebración eucarística, por lo que la representación del pavo real sobre un sello, que permita su aparición sobre la superficie de una oblea sagrada, es una cuestión perfectamente comprensible y aceptable, lo cual ayuda a entender mejor su representación sobre el sello cristiano-godo que presentamos aquí. Por otra parte, cuando en la iconografía paleocristiana se deseaba hacer alusión a las virtudes, para representar en concreto la templanza, se utilizaba también la figura del pavo real (Carmona 1998, 104).

El potente simbolismo y valor de la iconografía y la epigrafía que se muestran en esta pieza, la convierten en un elemento litúrgico fundamental, pues aquella hace presente a Cristo el Salvador, y esta a su madre la Beata Virgen María, los dos elementos más importantes del cristianismo a lo largo de toda su historia.

Tampoco es una casualidad la aparición de algunas hojas de palma flanqueando al pavo real de este sello, pues se trata de un elemento vegetal con el que comparte simbolismo y significado. La palma es un icono de origen pagano que representa la victoria, se apoya en la idea de que la palmera aparece en los oasis del desierto como ejemplo de vida, como prueba de victoria sobre la muerte. Por eso los primitivos cristianos entendieron que la palma estaba siempre viva, por ello conservaba todo el tiempo su color verde, símbolo de victoria sobre la muerte y clara representación de la vida eterna. Ejemplos de esta iconografía se pueden ver en pinturas de las Catacumbas de Roma, pero sobre todo en mosaicos tardíos, un buen ejemplo es el gran panel musivo absidal de la basílica de San Apollinare in Classe, en Rávena (Chelli 2004, 91, fig. 45). Además, desde el s. IV d. C., la palma simbolizaba la victoria de los mártires cristianos ante quienes les habían martirizado y asesinado, por ello aparecen en numerosas ocasiones con una palma entre sus manos (Chelli 2004, 90-91). Derivado de ello es que tras esa muerte y resurrección del cristiano se accede al Paraíso, por esto mismo la representación de la palma entre los cristianos alude también a aquel.

Una cuestión morfológica a destacar y explicar es la disposición y tipo de decoración en este sello eucarístico paleocristiano, que presenta una decoración cuyas figuras están en relieve, es decir, aparecen en positivo, por lo tanto cuando se presione el tampón sobre la superficie del pan eucarístico todavía sin cocer, se obtendrá una impresión en negativo. Esta circunstancia podría pensarse que no sería idónea para realizar impresiones sobre la pieza de harina cruda, pues cuando fuera depositada en el horno el pan se hincharía, se abombaría y por ello deformaría todas las figuras o signos impresos en su superficie. Sin embargo, hay que decir que ello puede ser evidentemente así en el caso de que se deba realizar la impresión sobre una masa de harina para obtener pan normal o un pastel, que al hincharse se convertirá en una pieza gruesa, abombada, por lo que seguro se deformaría toda la decoración impresa. Pero en el caso de tener que hacer la impresión en una masa de harina muy fina, muy delgada, totalmente plana, precisamente la que se debe elaborar para las obleas, la cocción de la misma no debe en ningún caso dar lugar al abultamiento o hinchazón de la pieza de pan, el pan litúrgico, que debe ser de un grosor muy delgada, circunstancia que facilita la fractio panis y su toma durante la comunión. Esto explica convincentemente que nuestro sello presente decoración en relieve, pues la iconografía que deje impresa será sobre una masa delgada de harina que nunca se hinchará o engrosará, no dando lugar a deformación de la decoración simbólica. Esto precisamente avala que se defienda que se trata de un sello, un stampo, para obtener obleas para su consagración litúrgica. Esta cuestión la hemos experimentado personalmente en un obrador de una panadería, además de haber localizado videos donde se contempla la 
producción actual de obleas que son grabadas con decoración en positivo impresa, que no se deforma con el calor recibido.

Respecto a su pertenencia a un conjunto de instrumental eucarístico relacionado con un edificio de culto, donde se desarrollase el rito cristiano aunque con anterioridad fuese grecooriental, ya hemos indicado al inicio de este trabajo la asociación de este sello cerámico con un lote importante de materiales bizantinos y otros quizá godos, que no serían desechados y continuarían en uso eucarístico en la iglesia de Elo (El Monastil).

En concordancia, ejemplo y apoyo de ello, se debe citar un hallazgo excepcional, se trata de que en el enclave altomedieval de Quattro Macine, en el Salento italiano (extremo sur de la península de Italia), se encontraron varios sellos eucarísticos, relacionados con dos iglesias, del que fuera el Arzobispado de Otranto, de esas dos iglesias parece que una era usada para el rito greco-bizantino, en una fecha de los siglos X-XI, es realmente interesante observar que en esta iglesia bizantina se halló una lancia o cuchillito de hierro, utilizada para cortar y trocear el pan eucarístico, junto al mismo se recogieron también dos cucharillas, una también de hierro, pero la otra de peltre, material que da lugar a un aspecto brillante, pulido y de imitar a la plata (Arthur 1997, 525526), que es precisamente como la hallada en El Monastil, al igual que ese cuchillito de hierro semejante también al de El Monastil, que como en ese hallazgo de Quattro Macine, aparecen como objetos juntos y acompañando a un sello cerámico eucarístico. Es pues la constatación de que el sello de El Monastil debía formar parte de un instrumental eucarístico, de su ahora iglesia goda, perteneciente a los inicios del s. VII d. C., vinculada a la sede episcopal elotana, o quizá fuese de fábrica bizantina pero usando epigrafía latina.

Después de haber realizado una detallada presentación de materiales arqueológicos, identificados como instrumental litúrgico y asociados a un contexto religioso cristiano que disponía de una iglesia, y teniendo en cuenta algunas de las publicaciones citadas en la bibliografía usada en este breve trabajo, es evidente que El Monastil, la ciuitas/castrum de Elo, no ofrece dudas de su naturaleza cultural y religiosa, que le relaciona directamente como un enclave del territorium de la cercana Ilici (la Alcudia, Elche), y su pertenencia al territorio bizantino regido por la también relativamente próxima capital bizantina, Carthago Spartaria, en Cartagena. Sería en ese indudable centro habitado por un grupo de bizantinos, donde surgió un complejo monástico oriental, que al ser conquistado el lugar y su territorio próximo interior por las tropas de los godos (hacia el 600 d. C.), habría permitido a su reino de Toledo crear un efímero obispado de frontera, lo que explica, según J. Vives (1961, 1-9) y todos los investigadores posteriores, que en las actas de los sinodales y concilios toledanos del s. VII aparezca la firma de un obispo Elotano (primera vez en el 610 bajo reinado de Gundemaro), y que cuando los bizantinos sean expulsados de Ilici y se restablezca aquí el antiguo episcopado visigodo ilicitano con todo su territorio, dará lugar a que se cerrara la sede elotana para ser trasladada y refundida con éste, como ilustra bien que desde entonces (años 620/625) los obispos firmantes en nuevas actas conciliares lo hagan apareciendo con la fórmula episcopus Ilicitano et Elotano, circunstancia que se prolongará hasta la llegada de los musulmanes (Llobregat 1973, 46-51; 1977, 94-96; 1983, 236-237; 1996, 69 y 74; Poveda 1991, 611-626; 1996a, 113-136; 2000a, 93-99; 2020; Peidro 2008, 263-276; 2008a, 303-320).

Precisamente un grupo de ellos se estableció en El Monastil, Elo, que no debe confundirse con la ciudad romano-goda de Ilinum/Ilvnum (Tolmo de Minateda, Hellín) creadora de un complejo monástico godo, erróneamente confundido inicialmente con la sede episcopal elotana, o como se viene defendiendo en las últimas décadas con la extrañamente identificada como eiotana (Abad 1993, 127-132; Abad y Gutiérrez 1997, 591600; Gutiérrez 2000, 481-501; Gutiérrez Abad y Gamo 2005, 345-368; Gutiérrez y Sarabia 2013, 
267-300; Lorenzo 2016, 265-305), cuando sin dificultad se puede identificar con la posterior madinat Iyi $(h) / I y y i(h) / I y y u(h)$ que es como aparece frecuente y correctamente citada en todas las versiones conocidas del texto del Pacto de Teodomiro de Oriola (Teudimer de Aurariola) (Carmona 2009, 5-27), en los que nadie ha podido demostrar la mención de una supuesta población goda o islámica denominada Eio, que tampoco aparece constatada epigráficamente ni en los diversos itineraria romanos ni altoimperiales, ni en ningún tipo de inscripción. Es decir, a día de hoy nadie puede demostrar fehacientemente que haya existido un centro urbano godo o islámico que se denominase Eio, por lo tanto es innecesario buscar su mención entre los obispados de las actas conciliares de Toledo o en los textos del Pacto de Teodomiro que citan sus medinas. Es patente que en esa documentación escrita tendrían que buscar la cita del topónimo o gentilicio de Ilinum, pero no aparece mencionado por ninguna parte, la razón es clara, en Ilinum/Tolmo de Minateda nunca hubo un obispado godo, por lo que los importantes restos de arquitectura religiosa goda han de asociarse a un más que probable monumental complejo monástico, de los siglos VI-VII (Poveda 2020; en prensa).

Se debe añadir que consecuentemente, quien no aparece incluida entre las medinas del Pacto es Elo, que habría perdido su condición de centro urbano aunque siguió habitado de algún modo, al menos por un modesto grupo de musulmanes, protagonista del profundo expolio de la iglesia que entonces era el centro de un monasterium de una exigua comunidad goda, el edificio fue desmontado y su cabecera rectangular con ábside convertido en una pequeña mezquita, creando además una comunidad islámica de monjes-soldados, como las que son llamadas en árabe almunastir, o más tarde ribat (rabita o rábida), circunstancia que no ofrece duda alguna de que es la razón de que el paraje donde está el despoblado, donde se halló el excepcional resto del disco cerámico con el sello litúrgico godo, se denomine hasta la actualidad El Monastil (Poveda 2007, 181-201).

\section{Bibliografía}

Abad Casal, L. 1993. Algunas novedades onomásticas de la ciudad de Ilunum (El Tolmo de Minateda, Hellín, Albacete). Antigüedad y Cristianismo 10, 127-132.

Abad Casal, L. y Gutiérrez Lloret, S. 1997. Iyih (El Tolmo de Minateda, Hellín, Albacete). Una civitas en el limes visigodo-bizantino. Antigüedad y Cristianismo 14, 591-600.

Alföldi, A. 1938. Tonmodel und Reliefmedaillons aus den Donailänder. Dissertationes Panonicae. Laureae Aquicenses I, Leizpig.

Arthur, P. 1997. Uno stampo eucarístico bizantino da Soleto (LE), Archeologia Medievale 24, 525530.

Balmaseda Muncharaz, L.J. 2007. En busca de las iglesias toledanas de época visigoda. En Hispania Gothorum. San Ildefonso y el Reino Visigodo de Toledo, 197-214. Toledo: Museo de Santa Cruz de Toledo.

Bisconti, F. 1979. Aspetti e significati del simbolo della fenice nella letteratura e nellarte del cristianesimo primitivo. Vetera Christianorum 16, 21-40.

Bisconti, F. 1991. Fenix (iconografía). En Di Berardino, A. (dir.), Diccionario Patrístico y de la Antigüedad Cristiana, t. 1 (A-I), 869-870. Salamanca: Institutum Patristicum Augustinanum - Roma. Ediciones Sigueme.

Carmona González, A. 2009. El sur de Albacete y los emplazamientos de Iyuh. Al-Basit 54, 5-27. Carmona Muela, J. 1998 Iconografía Cristiana. Guía para estudiantes, San Sebastián de los Reyes: Itsmo. 
Chalkia, E. 1991. Le mense paleocristiane: tipología e funzioni delle mense secondarie nel culto paleocristiano. Studi di Antichità Cristiana 46. Città del Vaticano: Pontificio Istituto di Archeologia Cristiana.

Chelli, M. 2004. Manuale dei simboli nell'arte. L'era paleocristiana e bizantina, Roma: EDUP.

Cortés y López, M. 1836. Diccionario geográfico histórico de la España antigua Tarraconense, Bética y Lusitana, t. 2. Madrid.

Deonna, W. 1919. Notes d'Archeologie Suisse. Decoration murale de Corsier. Anzeiger für Schweizerische Altertunskunde, NF.

Diego Barrado, L. 2010. La representación del ave fénix como imagen de la Renovatio de la Roma altomedieval. Anales de Historia del Arte 171, Extraordinario, 171-185.

Drexel, Fr. 1916. Crustulum et mulsum. Römisch-germanisches Korrespondenzblatt 9, 17-22.

Fernández Collado, A. 2007. La descensión de la Virgen María a Toledo y su manifestación en la catedral primada. En Hispania Gothorum. San Ildefonso y el Reino Visigodo de Toledo, 337352.Toledo: Quixote IV Centenario - Junta de Comunidades Castilla-La Mancha.

Ferrua, A. 1954-1955. Tre note di iconografia paleocristiana: la fenice sul rogo. En Miscellania G. Belvederi, 237-277. Città del Vaticano,

Galavaris, G. 1970. Bread and Liturgy: the Symbolism of Early Christian and Byzantine Bread Stamps, Madison-Milwaukee-London: University of Wisconsin Press.

García Moreno, L.A. 1981. El reino de Toledo. En Sayas Abengoechea, J.J. y García Moreno, L.A. (eds.), Romanismo y Germanismo. El despertar de los pueblos hispánicos, ss. IV-X. Historia de España, t. 2, 2, 1. Barcelona: Ed. Labor.

Gijón Gabriel, Ma . E. y Bustamante Álvarez, M. 2010. Los sellos romanos de Panadero: una aproximación a su estudio a partir de los depositados en el Museo Nacional de Arte Romano (Mérida). Huelva en su Historia 13, 15-30.

Gutiérrez Lloret, S. 2000. La identificación de Madinat Iyih y su relación con la sede episcopal Elotana. Nuevas perspectivas sobre viejos problemas. En Olcina, M. y Soler, J. (coords.), Scripta in Honorem Enrique Llobregat Conesa, 481-501. Alicante: Diputación Provincial de Alicante.

Gutiérrez Lloret, S., Abad Casal, L. y Gamo Parras, B. 2005. Eio, Iyyuh y el Tolmo de Minateda (Hellín, Albacete): de sede episcopal a madina islámica. En Gurt i Esparraguera, J. M. y Ribera i Lacomba, A. (coords.), VI Reunió d’Arqueologia Cristiana Hispànica. Les ciutats tardoantigues d'Hispania. Cristianització i topografia. València 8, 9 i 10 de maig de 2003, 345-370. Barcelona: Institut d'Estudis Catalans : Universitat de Barcelona.

Gutiérrez Lloret, S. y Sarabia Bautista, J. 2013. The episcopal complex of Eio - El Tolmo de Minateda (Hellín, Albacete, Spain). Architecture and spatial organization. 7 to 8 centuries AD. Hortus Artium Medievalium 19, 267-300.

Ihnat, K. 2019. Orígenes y desarrollo de la fiesta litúrgica de la Virgen María en Iberia. Anuario de Estudios Medievales 49(2), 619-643.

Jurlaro, R. 1961. Nuovi stampi eucaristici del Salento. Bolletino della Badia Greca di Grottaferrata $15,77-82$.

Lillo Carpio, P.A. 1981. Contribución al estudio de los sellos de panadero del Sureste. Memorias de Historia Antigua 5, 187-194.

Llobregat Conesa, E. A. 1973. Teodomiro de Oriola, su vida y su obra, Alicante: Caja de Ahorros Provincial.

Llobregat Conesa, E. A. 1977. La primitiva cristiandat valenciana. Segles IV al VIII, Valencia: L'Estel. 
Llobregat Conesa, E. A. 1983. Relectura del Ravennate: dos calzadas, una mansión inexistente y otros datos de la Geografía Antigua del País Valenciano. Lucentum 2, 225-242.

Llobregat Conesa, E. A. 1996. La provincia Carthaginense. Evolución y ciudades. Alebus 6, 57-76.

Lorenzo De San Román, L. 2016. Ecclesiae Ilicitanae, qui et Eiotanae, episcopus. Sobre la extensión y dualidad de la Sede episcopal de Ilici en la Antigüedad Tardía. Lucentum 35, 265-305.

Márquez Villora, J. C. y Poveda Navarro, A. M. 2000. Espacio religioso y cultura material en Elo (ss. IV-VII dC.). En V Reunió d'Arqueologia Cristiana Hispànica. Cartagena, 16-19 d'abril de 1998, 177-184. Barcelona: Institut d'Estudis Catalans : Universitat de Barcelona.

Olmo Enciso, L. 2007. Nuevos paisajes urbanos y consolidación del Estado en época visigoda. En Hispania Gothorum. San Ildefonso y el Reino Visigodo de Toledo, 161-180.Toledo: Quixote IV Centenario - Junta de Comunidades de Castilla-La Mancha.

Overbeck, J.A. 1866. Pompeji in seinen Gebäuden, Altertümern und Kunstwerken, Leipzig: Engelmann.

Pasqui, A. 1906). Ostia. Nuove scoperte presso il Casone. Notizie degli Scavi Antique, 357-373.

Peidro Blanes, J. 2008. La política administrativo-religiosa del estado visigodo en el Sureste: el caso de la creación de la sede episcopal Elotana. Espacio, Tiempo y Forma. Serie II. Historia Antigua 21, 303-320.

Peidro Blanes, J. 2008a. La región de la Orospeda tras Leovigildo. Organización y administración del territorio. Verdolay 11, 263-276.

Pessoa, M. 2017. ¿Fíbula o cuño litúrgico? de Conimbriga. En López Quiroga, J. y Martínez Tejera, A. M. (coords.), In tempore sueborum. El tiempo de los suevos en la Gallaecia (411-585): el primer reino medieval de Occidente, 189. La Coruña: Diputación de Orense.

Poveda Navarro, A. M. 1988. El poblado ibero-romano de "El Monastil. Introducción históricoarqueológica. Alicante: Ayuntamiento de Elda - Universidad de Alicante.

Poveda Navarro, A. M. 1991. La creación de la sede episcopal de Elo en la expansión toledana de fines del s. VI en el SE. Hispano. En Actas del XIV Centenario de III Concilio de Toledo (5891989), 611-626. Madrid.

Poveda Navarro, A. M. 1996. El Monastil: del oppidum ibérico a la civitas hispanorromana de Ello. En Actas XXIII Congreso Nacional de Arqueología (Elche, 1995), t. 1, 415-426. Elche: Ajuntament d'Elx.

Poveda Navarro, A. M. 1996a. La creación de la sede de Elo en la frontera visigodo-bizantina. En El espacio religioso y profano en los territorios urbanos de occidente (siglos V-VII) actas de las Jornadas. Internacionales la Sede de Elo, 1400 Años de su Fundación : Elda, 22-24 de abril de 1991, 113-136, Alebus 6. Elda: Museo Arqueológico Municipal del Ayuntamiento de Elda.

Poveda Navarro, A. M. 2000. Arquitectura sacra de la Carthaginensis Oriental durante la Antigüedad Tardía: las aportaciones de la Alcudia (Elche) y el Monastil (Elda). En Oliveira Jorge, V. (coord.), 3. ${ }^{\circ}$ Congresso de Arqueología Peninsular. UTAD, Vila Real, Portugal. Setembro de 1999, t. 6, 569-586. Porto: ADECAP.

Poveda Navarro, A. M. 2000a. El Obispado de Elo. En Los orígenes del Cristianismo en Valencia y su entorno, 93-96. Valencia: Ayuntamiento de Valencia.

Poveda Navarro, A. M. 2003. La iglesia paleocristiana de El Monastil (Elda, Alicante) en la provincia Carthaginense (Hispania). Hortus Artium Medievalium 9, 113-125.

Poveda Navarro, A. M. 2006. La cristianización del Valle de Elda. Épocas tardorromana y bizantinovisigoda. En Poveda Navarro, A. M. y Valero Escandell, J. R. (coords.), Historia de Elda, t. 1, 95115. Alicante: Caja de Ahorros del Mediterráneo - Ayuntamiento de Elda, Alicante.

Poveda Navarro, A. M. 2007. De monasterium visigodo a al-munastir islámico. El Monastil (Elda, Alicante), durante la Alta Edad Media. En Actas Congreso Monasteria et Territoria. 
Elites, edilicia y territorio en el Mediterráneo medieval (ss. V-XI), Tempus Reparatum, 181-201. Oxford: BAR International Series.

Poveda Navarro, A. M. 2009. El Monastil (Elda, Alicante). En El tiempo de los “Bárbaros". Pervivencia y transformación en Galia e Hispania (ss. V-VI dC.), Zona Arqueológica 11, 579-581.

Poveda Navarro, A. M. 2010. La romanización del oppidum contestano de Elo (El Monastil, Elda). En Poveda Navarro, A. M. y Uroz Sáez, J. (eds.), Actas Congreso La Iberia de los oppida ante su romanización (Elda, 2003), 65-86. Alebus 13, Universidad de Alicante - Museo Arqueológico de Elda.

Poveda Navarro, A. M. 2016. Un ejemplo de sincretismo religioso de la Antigüedad. Hércules - Cristo en la Hispania tardo-antigua. En Gasperini, V. (ed.), Vestigia. Miscellania di studi storico-religiosi in onore di Filippo Coarelli nel suo $80^{\circ}$ anniversario, 617-630. Stuttgart: Franz Steiner Verlag.

Poveda Navarro, A. M. 2019. Instrumentos eucarísticos de la iglesia del castrum bizantino de Elo (El Monastil, Elda). En López Vilar, J. (ed.), Tarraco Biennal. Actes 4t Congrés Internacional d'Arqueologia i Món Antic. VII Reunió d'Arqueologia Cristiana Hispànica. El cristianisme en l'Antiguitat Tardana. Noves perspectives, 305-312. Tarragona: Universitat Rovira i Virgili. Publicacions URV : Institut d'Estudis Catalans.

Poveda Navarro, A. M. 2020. El Tolmo de Minateda (Ilinum / Iyih, Hellín). Eio y la inexistente sede episcopal eiotana. La silla elotana se identifica con Elo (El Monastil, Elda). En Poveda Navarro, A. M. (ed.), Más que piedras. Revisiones de Hispania tardoantigua entre bizantinos y visigodos, Alebus 14-15, 99-183. Elda: Museo Arqueológico Municipal del Ayuntamiento de Elda.

Poveda Navarro, A. M. (en prensa) Lampadarios cristianos tardoantiguos de Hispania. Evidencias de Begastri (Cabezo Roenas, Cehegín) e Ilinum (Tolmo de Minateda, Hellín), Boletín del Museo Arqueológico Nacional.

Poveda Navarro, A. M. y Márquez Villora, J.C. 2006. La romanización del Valle de Elda. El Monastil. En Poveda Navarro, AM. y Valero Escandell, J.R. (coords.), Historia de Elda, t.1, 63 73. Alicante: Caja de Ahorros del Mediterráneo - Ayuntamiento de Elda, Alicante.

Poveda Navarro, A. M., Márquez Villora, J.C. y Peidro Blanes, J. 2013. La iglesia paleocristiana de "El Monastil" (Elda, Alicante) y su contexto arqueológico (siglos V-VII dC.). En Brandt, O. et alii (eds.), Actas XV Congressus Internationalis Archaeologiae Christianae (Toledo, 2008), t. 2, 1153-1165. Studi di Antichità Christiana 65. Roma: Pontificio Istituto di Archeologia Cristiana.

Reynolds, P. 1993. Settlement and Pottery in the Vinalopó Valley (Alicante, Spain) A.D. 400-700, Tempus Reparatum, 588, Oxford: BAR International Series.

Roldán Hervás, J. M. 1975. Itineraria Hispana. Fuentes antiguas para el estudio de las vías romanas en la Península ibérica, Valladolid - Granada: Universidad de Valladolid.

Sastre de Diego, I. 2010. Los primeros edificios cristianos de Extremadura. Sus espacios y elementos litúrgicos. Caelum in terra, Colección Ataecina. Mérida: Instituto de Arqueología de Mérida.

Sillières, P. 1990). Les voies de communication de l'Hispanie Meridionale. Paris: Publications du Centre Pierre Paris.

Vallejo Girvés, M. 1996. Las edificaciones de carácter religioso en los Aedificiis de Procopio: Septem y la dedicación a la Theotokos. Alebus 6, 319-327. Elda: Museo Arqueológico Municipal del Ayuntamiento de Elda.

Vallejo Girvés, M. 2012. La epigrafía latina y la propaganda política bizantina en el Mediterráneo occidental durante el siglo VI. Veleia 29, 71-82.

Van de Broek, R. 1972. The myth of Phoenix according to classical and early Christian tradition, Leiden: Brill.

Vives Gatell, J. 1961. Nuevas diócesis visigodas ante la invasión Bizantina. Spanische Forschungen $17,1-9$. 